\title{
A STUDY OF STATISTICAL MODELS APPLICATION FOR MIXTURE OF HIGH- FLOWING CONCRETE
}

\author{
Ming-Chih Li \\ Department of Civil Engineering, National Taiwan University, Taipei, Taiwan. \\ Yu-Sheng Chen \\ Department of Civil Engineering, National Taiwan University, Taipei, Taiwan. \\ Yin-Wen Chan \\ Department of Civil Engineering, National Taiwan University, Taipei, Taiwan., ywchan@ntu.edu.tw \\ Vihn Long Hoang \\ Department of Civil Engineering, National Taiwan University, Taipei, Taiwan.
}

Follow this and additional works at: https://jmstt.ntou.edu.tw/journal

Part of the Civil and Environmental Engineering Commons

\section{Recommended Citation}

Li, Ming-Chih; Chen, Yu-Sheng; Chan, Yin-Wen; and Hoang, Vihn Long (2012) "A STUDY OF STATISTICAL MODELS APPLICATION FOR MIXTURE OF HIGH-FLOWING CONCRETE," Journal of Marine Science and Technology. Vol. 20: Iss. 3, Article 12. DOI: $10.51400 / 2709-6998.1811$

Available at: https://jmstt.ntou.edu.tw/journal/vol20/iss3/12

This Research Article is brought to you for free and open access by Journal of Marine Science and Technology. It has been accepted for inclusion in Journal of Marine Science and Technology by an authorized editor of Journal of Marine Science and Technology. 


\title{
A STUDY OF STATISTICAL MODELS APPLICATION FOR MIXTURE OF HIGH-FLOWING CONCRETE
}

\author{
Ming-Chih Li, Yu-Sheng Chen, Yin-Wen Chan, and Vihn Long Hoang
}

Key words: High flowing concrete, statistical model, slump flow, RCPT.

\begin{abstract}
High flowing concrete (HFC) is defined as a concrete that exhibits a high deformability and a good resistance to segregation. The grade of workability for HFC is concrete slump flow that between 50 to $70 \mathrm{~cm}$. In the research, 21 statistically balanced concrete mixtures were investigated by statistical models, and discussed further the workability, strength and durability properties of concrete, which are responded by granulated ground blastfurnace slag (GGBS), Fly ash, waterbinder ratio (w/b) and superplasticizer (sp). The Box-Wilson central composite design (CCD) method is used in this study. The total binder content is $375 \mathrm{~kg} / \mathrm{m}^{3}$, and four independent variables such as percentage of GGBS as cement replacement (20 to $50 \%$ by mass), percentage of Fly ash as cement replacement ( 15 to $35 \%$ by mass), w/b (0.39 to 0.45$)$ and percentage of SP (1.0 to 1.4 by binder mass) are used for the design of HFC mixtures. The fresh properties of mortar and concrete, mechanical properties and durability characteristics of concrete are measured. Finally, the concrete slump flow model, $\mathrm{T}_{50}, 7-$, 28- and 90-day compressive strength model, the RCP (rapid chloride permeability) model, and Carbonation model are developed successfully. The proposed response models of HFC offer useful information regarding the mixture optimization.
\end{abstract}

\section{INTRODUCTION}

Concrete is the most important element of the infrastructure today and well-designed concrete can be a multi-functional material. However, the production of cement brings many harmful gases such as $\mathrm{CO}_{2}, \mathrm{NO}_{2}$, and $\mathrm{SO}_{2}$. It is an important subject to reduce the cement content of concrete. The traditional concrete is one kind of uneconomic concrete that with

Paper submitted 03/25/11; revised 04/02/12; accepted 05/01/12. Author for correspondence: Yin-Wen Chan (e-mail: ywchan@ntu.edu.tw).

Department of Civil Engineering, National Taiwan University, Taipei, Taiwan. high water to cement ratio and low workability is difficult to place, and some problems are easy to occur, like honeycomb and bleeding. To solve these problems, concretes with high workability and high durability, such as self-compacting concrete have recently been developed and applied. SCC is a special type of concrete with great self-compacting ability that can fill the formwork and vacancy among rebars without the need of vibration or compacting during the process of concrete placement. The multi-advantages of SCC had been produced with a high dosage of powder, as well as a high dosage of superplasticizer and well-graded aggregates. However, such concrete needs to increase more cost and cement content. Some problems such as the actual strength is much higher than the design strength and heat of hydration need be considered. It is uneconomical to use the SCC in general construction. Thus the HFC that developed with using industrial by-products such as Fly ash and GGBS to reduce the cement content of concrete has advantages in general construction.

HFC is a special type concrete with high slump flowing and high resistance to segregation. The workability index of HFC is slump flow, and the range of slump flow has been considered between 50 and $70 \mathrm{~cm}$ [1]. The difference between traditional concrete and HFC are high slump and high slump flow, the HFC was different from SCC that needed to be vibrated while placing. The high flowability can easily be achieved by adding performance $\mathrm{sp}$ to the concrete, the more dosage of $\mathrm{sp}$, the more slump flow. Reduction in viscosity and shear yield stress, which leads to increase the workability of concrete. On the other hand, it is a way to improve the workability of concrete by adjusting water to binder ratio, adding to mineral admixture such as GGBS and Fly ash. The stability will be reduced with the increase of flowability result in increased risk of coarse segregation, whether dynamic segregation or stable segregation. To enhance its stability so that the paste can maintain the coarse aggregates in uniform suspension, higher powder content is required [18]. An easy way to avoid segregation on chemical admixture addition is to increase the sand content by 4 to $5 \%$ at the cost of coarse aggregate [19]. To enhance the viscosity of mortar lead to decreased risk of coarse segregation by reducing the lubrication and friction between paste and fine aggregate. An alternative approach is 
to incorporate a viscosity-modifying admixture (VMA) to enhance the segregation resistance [6]. VMA is one kind of water-soluble polymer that can absorb free water in the fresh concrete result in enhancing viscosity of concrete. This research is aimed at developing HFC with low cement content. The workability can be arrived with using pozzolanic material replacement for cement, increasing the S/A and adjusting the sp. Furthermore, long term for mechanics properties and durability ability can be improved by adding pozzaolanic material replacement. Thus the influence of GGBS, Fly ash, sp and w/b on rheology, mechanical properties and durability ability of HFC which is important and the researches are required. For this purpose, the statistical method will be used to design to concrete mixtures variables and the analysis of experiment result.

The Response surface methodology (RSM) consists of a set of statistical methods that can be used to develop improvement or optimize products that had been used to investigate the fresh and harden properties of concrete mixtures in recent years [15, 21]. A factorial design was carried out to mathematically model the influence of four key parameters, including the content of cement, pulverized fuel ash, water to powder ratio and dosage of SP on filling and passing abilities, segregation and compressive strength. Finally, the medium strength selfcompacting concrete incorporating pulverized fuel ash was developed successfully [22]. The minimum use of waterreducing admixtures and to optimize use of Fly ash in SCC was investigated and the high-volume Fly ash SCC was successfully developed [15]. Four independent variables such as total binder content ( 350 to $450 \mathrm{~kg} / \mathrm{cm}^{3}$ ), percentage of Fly ash as cement replacement (30 to $60 \%$ by mass), percentage of high-range water-reducing admixtures $(0.1$ to $0.6 \%$ by solid mass), and water-binder ratio w/b (0.33 to 0.45$)$ were sued for the design of SCC mixtures. The fresh concrete properties were determined from slump flow, V-funnel flow, filling capacity, bleeding, air content, and segregation tests. The mechanical properties and durability ability of SCC such as compressive strength, rapid chloride permeability, freezingand-thawing resistance, and drying shrinkage were determined to evaluate the performance of SCC. The statistical models to predict workability, compressive strength and the rapid chloride permeability of SCC were developed and their performances were validated. Thus, the influence of multi-parameter on concrete such as fresh and harden properties can be analyzed by suing statistical treatment of experimental results. In this research, the statistical method was carried out to discuss the influence of GGBS as cement replacement, Fly ash as cement replacement, water to binder ratio and the dosage of chemical admixture on workability, compressive strength and durability properties of concrete.

\section{EXPERIMENTAL PLAN}

\section{Materials}

As for the materials used in this study, TYPE I Ordinary
Table 1. Chemical composition of cement, GGBS and Fly ash.

\begin{tabular}{c|l|l|l|l|l|l|c}
\hline & $\mathrm{SiO}_{2}$ & $\mathrm{Al}_{2} \mathrm{O}_{3}$ & $\mathrm{CaO}$ & $\mathrm{MgO}$ & $\mathrm{Fe}_{2} \mathrm{O}_{3}$ & $\begin{array}{c}\text { Finess } \\
\left(\mathrm{cm}^{2} / \mathrm{g}\right)\end{array}$ & $\begin{array}{c}\text { Loss on } \\
\text { ignition } \\
(\%)\end{array}$ \\
\hline cement & 20.89 & 5.61 & 63.87 & 2.93 & 3.13 & 3520 & - \\
\hline GGBS & 35 & 8.9 & 39 & 7.2 & 0.23 & 4100 & - \\
\hline Fly ash & 46 & 25.55 & 1.44 & 0.56 & 4.63 & - & $5.1 \%$ \\
\hline
\end{tabular}

Table 2. Physical properties of aggregates.

\begin{tabular}{c|c|c}
\hline Type & Fine aggregate & Coarse aggregate \\
\hline Specific gravity & 2.62 & 2.63 \\
\hline Fineness modulus & 2.71 & 6.61 \\
\hline Absorption $(\%)$ & 1.3 & 0.8 \\
\hline
\end{tabular}

Portland Cement (OPC), granulated ground blastfurnace slag (GGBS) with normal fineness, and F type Fly ash were used. The chemical compositions of OPC, GGBS, and Fly ash are shown in Table 1. Continuously graded gravel with a nominal particle size of $20 \mathrm{~mm}$ was used. Natural river sand with F.M of 2.71 is used as fine aggregate. Table 2 presents the basic physical properties of fine and coarse aggregate.

\section{Statistical Model and Mixture Design}

The Box-Wilson central composite design (CCD) method was used to design of mixture variables in this study. Four input factors were used in the test program such as X1 (percentage of GGBS as cement replacement by mass), X2 (percentage of Fly ash as cement replacement by mass), X3 (water to binder ratio), and X4 (percentage of SP as a percentage of mass of binder). The ranges of the input factors were set at 10 to $50 \%$ for X1, 5 to $35 \%$ for X2, 0.44 to 0.50 for X3, and 0.9 to $1.3 \%$ to $\mathrm{X} 4$. The CCD method consists of three portions: the fraction factorial portion, the center portion, and the axial portion. The interaction between two variables was presented by the fraction factorial portion and the axial portion allows the estimation of curvature. To repeat experiments for the central portion that is useful to estimate experiment error are needed.

The number of runs for fraction factorial portion was decided by $2 \mathrm{k}-1$, where $\mathrm{k}$ (= 4 in this study) is the number of factors. The total number of mixtures for fraction factorial portion was kept at $2^{4-1}=8$ with a different combination of coded value varying between +1 and -1 as shown in Table 3 . The number of runs for axial portion was set $2 \mathrm{k}=8$ for the experimental program. The coded value of portion is set at $\mathrm{F}^{1 / 4}=8^{1 / 4}=1.68$, where $\mathrm{F}$ is the number of runs in fraction factorial portion of the design. The center point portion are needed to get good estimation of pure experimental error. According to Schmidt and Launsby [20], the minimum number of center point can be obtained form $4 \times(F+1)^{1 / 2}-2 k$. A total of five runs (mixtures) was kept for the center point 
Table 3. Limit and coded value of factors (variables).

\begin{tabular}{|c|c|c|c|c|c|c|}
\hline \multirow{2}{*}{ Factor } & \multirow{2}{*}{ Range } & \multicolumn{5}{|c|}{ Coded value } \\
\hline & & -1.68 & -1 & 0 & +1 & +1.68 \\
\hline $\mathrm{X} 1$ & 10 to $50 \%$ & 10 & 18 & 30 & 42 & 50 \\
\hline $\mathrm{X} 2$ & 5 to $35 \%$ & 5 & 11 & 20 & 29 & 35 \\
\hline $\mathrm{X} 3$ & 0.39 to 0.45 & 0.39 & 0.40 & 0.42 & 0.44 & 0.45 \\
\hline $\mathrm{X} 4$ & 1.0 to $1.4 \%$ & 1 & 1.08 & 1.2 & 1.32 & 1.4 \\
\hline \multirow{2}{*}{$\mathrm{CCD}$ portion } & \multirow{2}{*}{ Mixture } & \multicolumn{5}{|c|}{ factors } \\
\hline & & $\mathrm{X} 1$ & $\mathrm{X} 2$ & & $\mathrm{X} 3$ & $\mathrm{X} 4$ \\
\hline Fractions factorial & $6,8,10,11,13,17,20,21$ & \pm 1 & \pm 1 & & \pm 1 & \pm 1 \\
\hline Center point & $1,2,9,15,18$ & 0 & 0 & & 0 & 0 \\
\hline Axial & $3,4,5,7,12,14,16,19$ & $0, \pm 1.68$ & $0, \pm 1.68$ & & $0, \pm 1.68$ & $0, \pm 1.68$ \\
\hline
\end{tabular}

Table 4. Mixture proportions of HFC (binder $=375 \mathrm{~kg} / \mathrm{m}^{3}$ ).

\begin{tabular}{|c|c|c|c|c|c|c|c|c|c|c|}
\hline \multirow{2}{*}{ Mixture no. } & \multirow{2}{*}{ Cement kg/m $\mathrm{m}^{3}$} & \multicolumn{2}{|c|}{ X1, GGBS } & \multicolumn{2}{|c|}{$\mathrm{X} 2$, Fly ash } & \multirow{2}{*}{$\mathrm{X} 3 \mathrm{w} / \mathrm{b}$} & \multirow{2}{*}{$\mathrm{X} 4 \mathrm{sp}, \%$} & \multirow{2}{*}{ Water $\mathrm{kg} / \mathrm{m}^{3}$} & \multicolumn{2}{|c|}{ Aggregate $\mathrm{kg} / \mathrm{m}^{3}$} \\
\hline & & $\%$ & $\mathrm{~kg} / \mathrm{m}^{3}$ & $\%$ & $\mathrm{~kg} / \mathrm{m}^{3}$ & & & & Coarse & fine \\
\hline 1 & 187.5 & 0.30 & 112.5 & 0.20 & 75.0 & 0.47 & 1.10 & 176 & 798 & 940 \\
\hline 2 & 187.5 & 0.30 & 112.5 & 0.20 & 75.0 & 0.47 & 1.10 & 176 & 798 & 940 \\
\hline 3 & 131.3 & 0.30 & 112.5 & 0.35 & 131.3 & 0.47 & 1.10 & 176 & 775 & 940 \\
\hline 4 & 262.5 & 0.10 & 37.5 & 0.20 & 75.0 & 0.47 & 1.10 & 176 & 804 & 940 \\
\hline 5 & 187.5 & 0.30 & 112.5 & 0.20 & 75.0 & 0.50 & 1.10 & 188 & 768 & 940 \\
\hline 6 & 109 & 0.42 & 157.1 & 0.29 & 108.5 & 0.45 & 0.98 & 170 & 799 & 940 \\
\hline 7 & 112.5 & 0.50 & 187.5 & 0.20 & 75.0 & 0.47 & 1.10 & 176 & 793 & 940 \\
\hline 8 & 266 & 0.18 & 67.9 & 0.11 & 41.5 & 0.45 & 0.98 & 170 & 833 & 940 \\
\hline 9 & 187.5 & 0.30 & 112.5 & 0.20 & 75.0 & 0.47 & 1.10 & 176 & 798 & 940 \\
\hline 10 & 266 & 0.18 & 67.9 & 0.11 & 41.5 & 0.45 & 1.22 & 170 & 833 & 940 \\
\hline 11 & 176 & 0.42 & 157.1 & 0.11 & 41.5 & 0.49 & 1.22 & 183 & 791 & 940 \\
\hline 12 & 243.8 & 0.30 & 112.5 & 0.05 & 18.8 & 0.47 & 1.10 & 176 & 822 & 940 \\
\hline 13 & 199 & 0.18 & 67.9 & 0.29 & 108.5 & 0.49 & 0.98 & 183 & 770 & 940 \\
\hline 14 & 187.5 & 0.30 & 112.5 & 0.20 & 75.0 & 0.47 & 1.30 & 176 & 798 & 940 \\
\hline 15 & 187.5 & 0.30 & 112.5 & 0.20 & 75.0 & 0.47 & 1.10 & 176 & 798 & 940 \\
\hline 16 & 187.5 & 0.30 & 112.5 & 0.20 & 75.0 & 0.47 & 0.90 & 176 & 798 & 940 \\
\hline 17 & 109 & 0.42 & 157.1 & 0.29 & 108.5 & 0.45 & 1.22 & 170 & 799 & 940 \\
\hline 18 & 187.5 & 0.30 & 112.5 & 0.20 & 75.0 & 0.47 & 1.10 & 176 & 798 & 940 \\
\hline 19 & 187.5 & 0.30 & 112.5 & 0.20 & 75.0 & 0.44 & 1.10 & 165 & 828 & 940 \\
\hline 20 & 199 & 0.18 & 67.9 & 0.29 & 108.5 & 0.49 & 1.22 & 183 & 770 & 940 \\
\hline 21 & 176 & 0.42 & 157.1 & 0.11 & 41.5 & 0.49 & 0.98 & 183 & 791 & 940 \\
\hline
\end{tabular}

portion with ' 0 ' coded value. The final coded value is set at five different levels such as $-1.68,-1,0,+1$, and +1.68 as shown in Table 3. The mixture proportions of $21 \mathrm{HFC}$ mixtures are presented in Table 4 . The amount of fine aggregate was kept constant at $940 \mathrm{~kg} / \mathrm{m}^{3}$ while the quantity of coarse aggregate varied as the mixture design procedure was based on absolute volume method.

\section{Preparation and Casting of Test Specimens for HFC}

All concrete mixtures were prepared in 70-1 batches in a horizontal axis concrete mixer. After the mixing, the fresh concrete tests such as slump flow test, $\mathrm{T}_{50}$ test and air content test were conducted. From each batch, nine $10 \times 20 \mathrm{~cm}$ cylinders for compressive strength, three $10 \times 20 \mathrm{~cm}$ cylinders for rapid chloride permeability test, three $10 \times 20 \mathrm{~cm}$ cylinders for carbonation test were cast. All HFC specimens were cast that divided into three layers with hand compaction 5 times per layer. After casting, all the specimens were covered with plastic sheets and water-saturated burlap, and left at room temperature for $24 \mathrm{~h}$. The specimens were demolded and transferred to the moist-curing room maintained at $23^{\circ} \mathrm{C}$ and $100 \%$ relative humidity until testing. 


\section{Tests on Fresh Properties of HFC}

The flowability and workability of HFC were conducted by slump flow and $\mathrm{T}_{50}$ that the time of slump flow to reach a diameter $500 \mathrm{~mm}\left(\mathrm{~T}_{50}\right)$. The $\mathrm{T}_{50}$ test of concrete performed in accordance with ASTM C1611 [2]. For the slump flow, the spread diameters were measured for the average of two measurements at right angles to each other, and were recorded to the nearest $10 \mathrm{~mm}$. The slump flow also was carried out by ASTM C1611 [2]. As chong $\mathrm{Hu}$ [7] supposes, the slump value over $8 \mathrm{~cm}$ and without heavy segregation behaves as a Bingham material in the steady state. Slump flow of concrete was control by shear yield stress and viscosity. The slump flowing was not observed until the shear stress yield decreased lower than inward shear stress of concrete. The lower shear yield stress of fresh concrete results in the higher slump. HFC is one kind of concrete of large slump and high flow, including lower shear yield stress. Moreover, the fluid rate of flow of HFC was affected by viscosity of mortar. It is the important role played by the viscosity of HFC in considering segregation resistance. Thus, $\mathrm{T}_{50}$ in our study is regarded as an index of viscosity. The air content was determined according to ASTM C231 [3].

\section{Compressive Strength and Durability of HFC}

Concrete compressive strength was determined according to ASTM C39 [4] for concrete samples. The compressive strength was measured for 7,28 , and 90 days. The average compressive strength of three $100 \times 200 \mathrm{~mm}$ cylinders was considered for each age. The rapid chloride permeability (RCPT) test is fully described in ASTM C 1202 [5] at an age of 90 days. Samples were prepared by cutting and discarding $25 \mathrm{~mm}$ slices from the top of $100 \times 200 \mathrm{~mm}$ cylinders, and the remaining section cut into $50 \mathrm{~mm}$-thick specimens and prepared as per ASTM C 1202 [5]. Each specimen was the placed between two cells filled with $0.3 \mathrm{~N} \mathrm{NaOH}$ and $3.0 \% \mathrm{NaCl}$ solutions. The total charge in coulombs passed in $6 \mathrm{~h}$ through the $50 \mathrm{~mm}$-thick specimens was considered as the resistance of the specimen to chloride ion penetration. An accelerated carbonation test was performed according to the method designed by Papadakis et al. [14] and the carbonation depth was determined with phenolphthalein test by RILEM CPC-18 [16]. Phenolphthalein is mixed as a solution of $1 \%$ in $70 \%$ ethyl alcohol. Before spraying, the surface of concrete needed to been cleaned. Phenolphthalein is a basic-base indicator that turns colorless in acidic solutions and pink in basic solutions when the $\mathrm{pH}$ is above a value of 9.5. The carbonation depth can be measured on the colorless zone.

\section{RESULTS AND DISCUSSION}

\section{Fresh Properties}

Test results of slump flow, $\mathrm{T}_{50}$, and air content are presented in Table 5. All of the concrete mixtures except mixtures 5, 6, 7, $8,11,16$, and 19 are qualified as HFC because the exhibited satisfactory slump flow between 50 and $70 \mathrm{~cm}$. The segrega- tions were not observed among mixtures 7, 11, and 14 that slump-flow were slightly larger than $70 \mathrm{~cm}$. Mixture 5, which had a slight segregation and exhibited a large slump flow of $73.5 \mathrm{~cm}$. The coarse segregation, including dynamic segregation and stability segregation can be controlled by viscosity of concrete. The degree of viscosity was estimated to the time of $\mathrm{T}_{50}$ or the $\mathrm{v}$-funnel time. The targets of $\mathrm{T}_{50}$ and $\mathrm{V}$-funnel time are proposed to SCC about 3 to $15 \mathrm{~s}$ and 7 to $20 \mathrm{~s}$ (JSCE 1998) [10]. The $T_{50}$ of mixtures $6,8,16$, and 19 were not recorded as the slump flow of concrete was not reaching 500 $\mathrm{mm}$ to measure. All other mixtures exhibited excellent $\mathrm{T}_{50}$ between 3.2 to $12.6 \mathrm{~s}$. On the other hand, all of mixtures were exhibited an air content of lower than $4 \%$.

\section{Compressive Strength and Durability}

The compressive strengths for different water to binder ratio and different quantities of pozzolanic materials as cement replacement of concrete specimens at the age of 7, 28, and 90 days are presented in Table 5. For 7-day strengths were between 180 to $340 \mathrm{kgf} / \mathrm{cm}^{2}$ and incorporating pozzolanic materials in concretre decreases the compressive strength from 334 to 181 and from 216 to $180 \mathrm{kgf} / \mathrm{cm}^{2}$, respectively such as mixture 12, 3, 4, and 7. For 28-day compressive strengths of all HFC were between 280 and $470 \mathrm{kgf} / \mathrm{cm}^{2}$. Quite a few pozzolanic effect of GGBS in concrete was observed, which the compressive strength of mixture 1 approximated to mixture 4 even though the addition of GGBS more than mixture 4. For 90-day compressive strength of all HFC were between 390 and $570 \mathrm{kgf} / \mathrm{cm}^{2}$, all concrete mixtures strengths more than 7 to $45 \%$ of 28 -day strengths. It show that the compressive strength were still increasing by pozzolanic effect in a long term. The results are consistent with another observation, which the activity of Fly ash much lower than GGSB.

The durability of the HFC, the rapid chloride permeability test (RCPT) and the carbonation test were carried out. All of the concrete mixtures except mixtures 5 and 12 appeared to be very low (ASTM C1202) [5] and ranged between 435 and 1120 coulombs of all mixtures in Table5. The influences of the charge passed are the amount of pozzolanic materials such as GGBS and Fly ash and water to binder ratio in this study. The total charge passed decreases with an increase of percentage of GGBS and Fly ash as cement replacement and a decrease of water to binder ratio. The results show that incorporates pozzolanic materials in HFC has a lower chloride ion penetration. The carbonation of HFC, the carbonation depth increase with increasing the percentage of pozzolanic materials as cement replacement and water to binder ratio, and the water to binder affects carbonation seriously.

\section{Development of Statistical Models}

An empirical statistical model was thought to be a useful design tool to optimize the mixture of concrete. The statistical model was used to optimize self-consolidating concrete with limestone $[11,8]$. In the study, the results of experiments such as the concrete fresh properties, compressive strength, and 
Table 5. Properties of fresh concretes, compressive strengths, and durability ability.

\begin{tabular}{|c|c|c|c|c|c|c|c|c|c|}
\hline \multirow{3}{*}{ No. } & \multicolumn{3}{|c|}{ Workability properties } & \multicolumn{3}{|c|}{ Compressive Strength } & \multicolumn{3}{|c|}{ Durability properties } \\
\hline & \multirow{2}{*}{$\begin{array}{c}\text { Slump flow } \\
(\mathrm{cm})\end{array}$} & \multirow{2}{*}{$\begin{array}{c}\mathrm{T}_{50} \\
(\mathrm{sec})\end{array}$} & \multirow{2}{*}{$\begin{array}{c}\text { Air content } \\
(\%)\end{array}$} & \multirow{2}{*}{$\begin{array}{c}\text { 7-day } \\
\left(\mathrm{kgf} / \mathrm{cm}^{2}\right)\end{array}$} & \multirow{2}{*}{$\begin{array}{c}28 \text {-day } \\
\left(\mathrm{kgf} / \mathrm{cm}^{2}\right)\end{array}$} & \multirow{2}{*}{$\begin{array}{c}\text { 90-day } \\
\left(\mathrm{kgf} / \mathrm{cm}^{2}\right)\end{array}$} & \multicolumn{2}{|c|}{ RCP } & \multirow{2}{*}{$\begin{array}{l}\text { Carbonation } \\
\text { Depth }(\mathrm{mm})\end{array}$} \\
\hline & & & & & & & Coulombs $(\mathrm{C})$ & Rating & \\
\hline 1 & 67 & 6.53 & 3.2 & 255.4 & 381.1 & 475 & 644 & Very low & 10.4 \\
\hline 2 & 66 & 7.02 & 2.9 & 251.2 & 393.5 & 465 & 620 & Very low & 10.9 \\
\hline 3 & 68.5 & 7.56 & 3.2 & 181.1 & 304.4 & 415 & 493 & Very low & 18.3 \\
\hline 4 & 58 & 9.31 & 3.2 & 261.1 & 385.2 & 433 & 937 & Very low & 7.6 \\
\hline 5 & 73.5 & 3.22 & 2.9 & 218.6 & 321.8 & 389 & 1019 & Low & 13.3 \\
\hline 6 & 38 & $\mathrm{Nr}$ & 2.1 & 213.9 & 316.0 & 437 & 510 & Very low & 13.8 \\
\hline 7 & 71 & 4.22 & 2.8 & 186.3 & 325.8 & 403 & 620 & Very low & 17.8 \\
\hline 8 & 33 & $\mathrm{Nr}$ & 2.1 & 322.4 & 460.3 & 569 & 759 & Very low & 8.3 \\
\hline 9 & 69 & 6.82 & 2.7 & 248.3 & 374.7 & 471 & 654 & Very low & 11.1 \\
\hline 10 & 63 & 12.63 & 2.3 & 309.6 & 415.5 & 538 & 813 & Very low & 8.4 \\
\hline 11 & 72 & 4.34 & 2.8 & 252.2 & 367.2 & 437 & 879 & Very low & 12.3 \\
\hline 12 & 64 & 6.25 & 2.4 & 334.4 & 414.8 & 483 & 1120 & Low & 6.1 \\
\hline 13 & 56 & 5.97 & 2.8 & 240.0 & 312.6 & 423 & 813 & Very low & 13.5 \\
\hline 14 & 72 & 6 & 2.4 & 251.7 & 395.3 & 483 & 530 & Very low & 10.0 \\
\hline 15 & 65 & 6.43 & 3.0 & 263.4 & 387.5 & 461 & 680 & Very low & 10.2 \\
\hline 16 & 44.5 & $\mathrm{Nr}$ & 2.2 & 300.8 & 427.2 & 457 & 629 & Very low & 9.6 \\
\hline 17 & 69 & 6.35 & 2.7 & 193.0 & 289.0 & 419 & 451 & Very low & 14.0 \\
\hline 18 & 67 & 6.44 & 3.3 & 243.6 & 375.6 & 481 & 678 & Very low & 10.5 \\
\hline 19 & 42 & $\mathrm{Nr}$ & 2.4 & 317.1 & 470.4 & 572 & 435 & Very low & 5.9 \\
\hline 20 & 69 & 4.01 & 3.4 & 194.2 & 289.9 & 400 & 828 & Very low & 14.0 \\
\hline 21 & 57.5 & 7.66 & 3.4 & 223.8 & 344.8 & 425 & 814 & Very low & 11.3 \\
\hline
\end{tabular}

Nr: not recorded.

durability properties were analyzed with the statistical method to set up the slump flow model, $\mathrm{T}_{50}$ model, compressive strength models, RCP model, and carbonation model. The STATA statistical software was used to derive several models by least square approach. The statistical models can be used to evaluate the influences of the BBGS as cement replacement, the Fly ash as cement replacement, water to binder ratio, and SP on the workability, the compressive strength, and the durability.

In addition, the statistical inference based by OLS will be invalid when ignoring the potential problem of heteroskedasticity. This paper checks whether the estimated variance of the residuals in the estimation regression are same by using Breusch-Pagan test $[9,23]$. The paper weights the standard error of estimators of OLS by using Heteroskedasticity-robust standard error proposed by White (1980) to find the valid inference when the sample that we are considered displays the non-constant error variance. Two-level fractional factorial design for four independent variables was used in the study. The basic model is as follow Eq. (1) and the parameters of the derived models are given in Table 6 . The $p$-values of parameters estimated within the statistical model are required less than 5\%, implying that the probabilities of error decisions with hypotheses, which the estimations of coefficients are large the given value, are less than $5 \%$. In terms of model selection, the seven major models are chose by comparing the values of the square of the correlation coefficient $\left(\mathrm{R}^{2}\right)$.

$$
\begin{aligned}
\mathrm{Y}=\mathrm{cons} & +\alpha_{1} \mathrm{sc}+\alpha_{2} \mathrm{fc}+\alpha_{3} w b+\alpha_{4} \mathrm{sp}+\alpha_{11} \mathrm{sc}^{2}+\alpha_{22} \mathrm{fc}^{2} \\
& +\alpha_{33} \mathrm{wb}^{2}+\alpha_{44} \mathrm{sp}^{2}+\alpha_{12} \mathrm{scfc}+\alpha_{13} \mathrm{scwb}+\alpha_{14} \mathrm{scsp} \\
& +\alpha_{23} \mathrm{fcwb}+\alpha_{24} \mathrm{fcsp}+\alpha_{34} \mathrm{wbsp}
\end{aligned}
$$

Here, $\mathrm{sc}=\mathrm{GGBS} / \mathrm{cement}$

$$
\begin{aligned}
& \text { fc }=\text { Fly ash/cement } \\
& \text { wb: water-binder ratio } \\
& \text { sp: chemical admixture }(\%)
\end{aligned}
$$

In the seven selected model, including Slump Flow, $\mathrm{T}_{50}, 7-\mathrm{d}$ strength, 28-d strength, 90-d strength, RCP, Carbonation, statistical values of the Breusch-Pagan test for checking the variances with heteroskedasticity are, respectively, 5.93 $(p$-value $=0.0149), 3.42(p$-value $=0.0642), 0.06(p$-value $=$ $0.801), 0.01(p$-value $=0.937), 1.36(p$-value $=0.2444), 0.7$ $(p$-value $=0.4022), 0.33(p$-value $=0.56), 5.93(p$-value $=$ $0.0149)$.

The statistical values of Slump Flow and $\mathrm{T}_{50}$ models are statistically significant at least the $10 \%$, implying that these two models have the problems with non-constant variances of 
Table 6. Parameter estimates of al derived models.

\begin{tabular}{c|c|c|c|c|c|c|c}
\hline & Slump flow $(\mathrm{cm})$ & $\mathrm{T}_{50}(\mathrm{~cm})$ & 7 -day f'c & 28-day f'c & 90-day f'c & RCP $(\mathrm{C})$ & Carbonaion \\
\hline R-squared & 0.9841 & 0.9945 & 0.9324 & 0.9315 & 0.9498 & 0.9691 & 0.9717 \\
\hline Adjusted R-squared & 0.9646 & 0.9909 & 0.9034 & 0.9087 & 0.9283 & 0.9485 & 0.9595 \\
\hline F-value & 75.23 & 197.01 & 32.18 & 40.8 & 44.15 & 47.03 & 79.97 \\
\hline Prob $>$ F & 0 & 0 & 0 & 0 & 0 & 0 \\
\hline const. & -3918.52 & 5778.682 & 310.6529 & 1757.961 & 2545.29 & -5404.14 & 36.05242 \\
\hline$\alpha_{1}$ & NS & -142.317 & 1318.169 & NS & NS & 4256.165 & -94.795 \\
\hline$\alpha_{2}$ & -448.707 & NS & NS & NS & -1481.67 & -1661.14 & -151.577 \\
\hline$\alpha_{3}$ & 13017.15 & -18116.5 & NS & -2770.49 & -4437.22 & NS & NS \\
\hline$\alpha_{4}$ & 1533.442 & -2371.67 & NS & -77.0082 & NS & 5850.351 & NS \\
\hline$\alpha_{11}$ & -24.8926 & NS & -42.9032 & -62.2786 & -71.5745 & 297.1863 & NS \\
\hline$\alpha_{22}$ & -33.0688 & NS & NS & -127.543 & NS & 1011.15 & NS \\
\hline$\alpha_{33}$ & -11458.5 & 14388.57 & NS & NS & NS & 16463.95 & -135.024 \\
\hline$\alpha_{44}$ & -245.315 & 295.9917 & NS & NS & NS & -2684.4 & NS \\
\hline$\alpha_{12}$ & 56.96969 & 5.426913 & NS & NS & NS & NS & 7.281582 \\
\hline$\alpha_{13}$ & 49.39012 & 290.0101 & -3273.24 & 222.7686 & NS & -10313.6 & 201.0092 \\
\hline$\alpha_{14}$ & NS & NS & 256.2982 & 358.664 & 111.4937 & NS & NS \\
\hline$\alpha_{23}$ & 943.0059 & NS & 873.0213 & NS & 3419.652 & NS & 336.3375 \\
\hline$\alpha_{24}$ & NS & NS & -529.087 & NS & -190.886 & NS & NS \\
\hline$\alpha_{34}$ & -1938.65 & 3515.038 & NS & NS & NS & NS & NS \\
\hline
\end{tabular}

NS: nonsignificant.

the residuals in the estimation regressions. The paper further adjusts the variance of standard error in the Slump Flow and $\mathrm{T}_{50}$ model by using Heteroskedasticity-robust standard error proposed by White (1980). The empirical results of seven models are respected in Fig. 5. According to the index of R2, the overall extent of explanation in these seven models are, respectively, 0.984, 0.995, 0.932, 0.932, 0.950, 0.969, and 0.972 , implying that the variables that we are considered in the models can account for $90 \%$ of the variance in the left-side variables. Moreover, statistical values of the test for the whole model (F-value) are significant at the $1 \%$ level, reflecting that our model have, in some extent, considerable explanations.

\section{Slump Flow Models of HFC:}

The HFC was defined by Architectural Institute of Japan that slump flow was between 50 and $70 \mathrm{~cm}$ and no segregation to occur in fresh concrete. The flowing ability was affected by a lot of variables such as the combination of binder, water to binder ratio, the dosage of sp, fine aggregate to total aggregate, and fineness modulus (FM) of sand. The composites of binder, water to binder ratio, and dosage of sp were considered in the research and the statistical method was used to set up slump flow model for the effective analysis. The proposed slump flow model is as follows:

$$
\begin{aligned}
\text { Slump Flow }= & \text { cons }+\alpha_{2} f c+\alpha_{3} w b+\alpha_{4} \mathrm{sp}+\alpha_{12} \mathrm{scfc} \\
& +\alpha_{13} \mathrm{scwb}+\alpha_{23} \mathrm{fcwb}+\alpha_{34} w b s p \\
& +\alpha_{11} \mathrm{sc}^{2}+\alpha_{22} \mathrm{fc}^{2} \alpha_{33} \mathrm{wb}^{2}+\alpha_{44} \mathrm{sp}^{2}
\end{aligned}
$$

A typical response chart for the slump flow with a binder content $375 \mathrm{~kg} / \mathrm{m}^{3}, 30 \%$ replacement of cement with GGBS, $20 \%$ replacement of cement with Fly ash is illustrated in Fig. 1. At given binder content and percentage of GGBS and Fly ash replacement as cement, desired slump flow can be predicted for different combinations of $w / b$ and chemical admixture. Fig. 2 shows the influence of percentage of GGBS replacement as cement on slump flow of HFC. At given binder content, the $20 \%$ of Fly ash replacement as cement, and $\mathrm{w} / \mathrm{b}=0.47$, increasing the percentage of GGBS replacement as cement can increase the slump flow substantially at any chemical admixture content. For example the slump flow is in $100 \mathrm{~mm}$ increment with an increase from $20 \%$ to $40 \%$ in GGBS replacement. The Fig. 3 show that the influence of Fly ash replacement on slump flow. The proportion of the binder content, the $\mathrm{w} / \mathrm{b}$, and the GGBS replacement are maintained at $375 \mathrm{~kg} / \mathrm{m}^{3}, 0.47$, and $30 \%$ respectively, increasing the Fly ash replacement can increase the slump flow at any sp content. The slump flow can be increased about $5 \mathrm{~cm}$ while the Fly ash is in $20 \%$ increment. The Figs. 4 and 5 present a feasibility result that the slump flow can be maintained by using GGBS and Fly ash to reduce the dosage of sp. As can be seen from Fig. 4, the slump flow is maintained $600 \mathrm{~mm}$ with increasing $20 \%$ GGBS replacement to reduce $0.08 \%$ by weigh of binder of the sp. The similar behavior can be observed in the Fig. 5, which the dosage of sp can be reduce $0.004 \%$ with the $20 \%$ increment of Fly ash to main the slump flow of $60 \mathrm{~cm}$. 


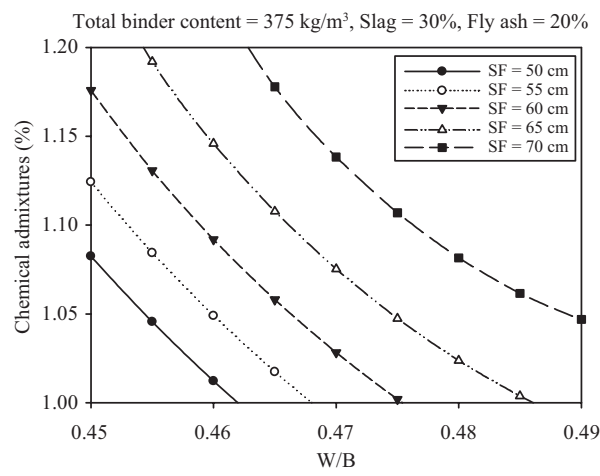

Fig. 1. Typical response chart for prediction of slump flow.

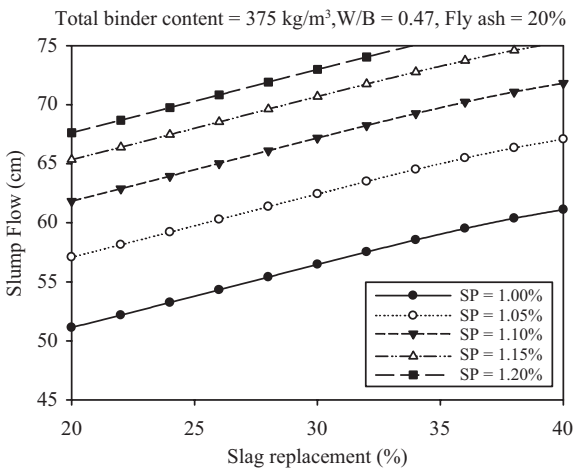

Fig. 2. Influence of GGBS replacement on slump flow.

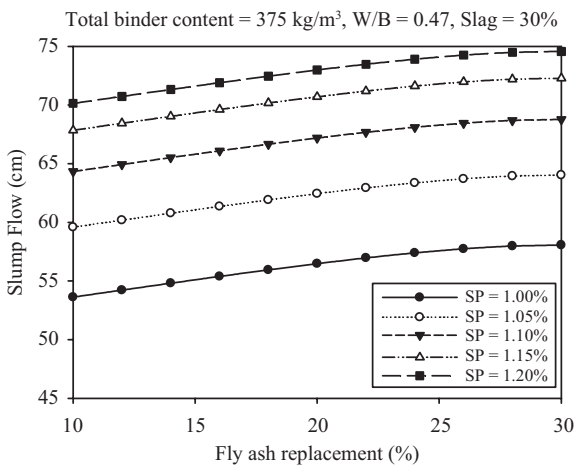

Fig. 3. Influence of Fly ash replacement on slump flow.

\section{$\mathbf{T}_{50}$ Model of HFC:}

The time of slump flow to reach a diameter $50 \mathrm{~cm}$ can be considered to evaluation of the plastic viscosity of concrete. The more time of $\mathrm{T}_{50}$ the higher viscosity, the higher viscosity can maintain the stable of HFC without segregation. The target of $\mathrm{T}_{50}$ is proposed to SCC about 3 to $15 \mathrm{~s}$. In the research, the $\mathrm{T}_{50}$ of all concrete mixtures except the mixtures that can't reach a diameter $500 \mathrm{~mm}$ are between 3 and $15 \mathrm{~s}$. The derived statistical model of $\mathrm{T}_{50}$ is given in Eq. (3). A chart was presented to predict the $\mathrm{T}_{50}$ of HFC is shown in Fig. 6 . At given binder content, GGBS replacement and Fly ash re-

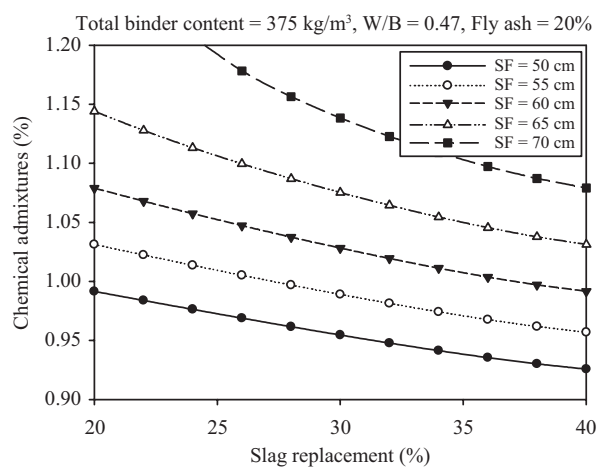

Fig. 4. Influence of BBGS on chemical admixture demand.

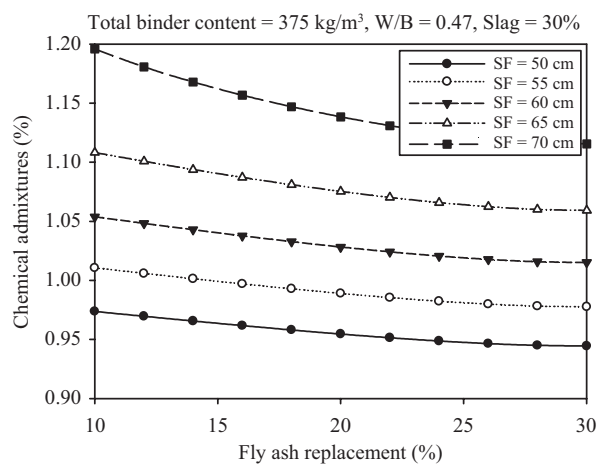

Fig. 5. Influence of Fly ash on chemical admixture demand.

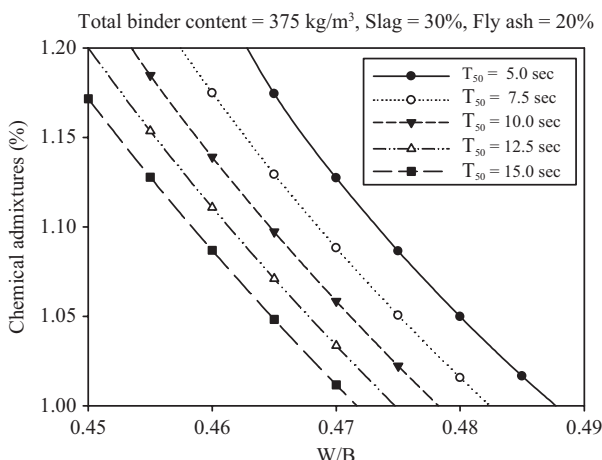

Fig. 6. Typical response chart for prediction of $T_{50}$ •

placement, the $\mathrm{T}_{50}$ can be predicted for different combinations or $\mathrm{w} / \mathrm{b}$ and sp. The $\mathrm{T}_{50}$ can be decreased while the $\mathrm{w} / \mathrm{b}$ and the dosage of sp are increased. The Fig. 7 presented the influence of $\mathrm{T}_{50}$ on GGBS replacement and $\mathrm{sp}$, which the increment of GGBS replacement and the sp result in reducing the $T_{50}$ of HFC. Moreover, the $\mathrm{T}_{50}$ is affected by sp is larger than GGBS replacement.

At given $\mathrm{w} / \mathrm{b}=0.47,30 \%$ and $20 \%$ Fly ash replacement, the $\mathrm{T}_{50}$ can be reduced $2 \mathrm{~s}$ with an increase $30 \%$ in GGBS replacement. The influence of $\mathrm{T}_{50}$ on Fly ash replacement under different dosage of sp were shown in Fig. 8 at given $\mathrm{w} / \mathrm{b}=0.47$ and $30 \%$ GGBS replacement. A tendency can be 


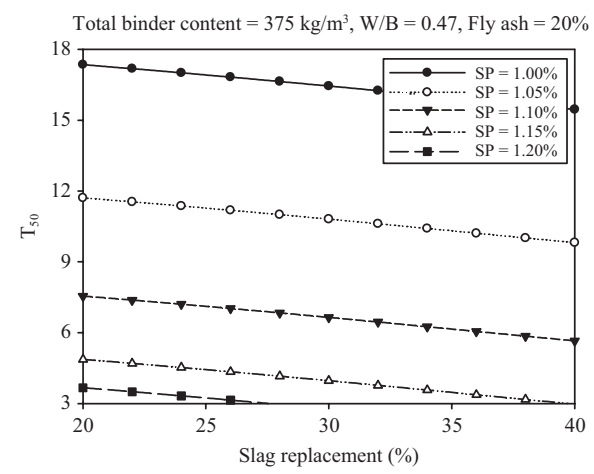

Fig. 7. Influence of GGBS replacement on $T_{50}$.

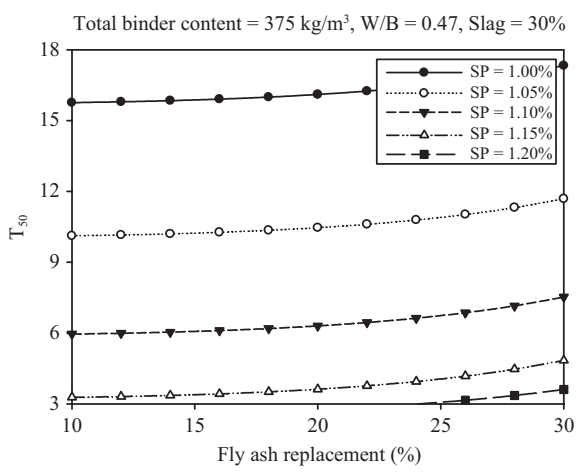

Fig. 8. Influence of Fly ash replacement on $T_{50}$.

observed in Fig. 8, which $\mathrm{T}_{50}$ can be increased with the increment of Fly ash replacement. It points out that the viscosity can be increased with Fly ash. From the above results, the responses of $\mathrm{T}_{50}$ were affected by $\mathrm{w} / \mathrm{b}$ and $\mathrm{sp}$ are larger than GGBS and Fly ash replacement, and the $\mathrm{T}_{50}$ of HFC can be designed with the combination of the four variables.

$$
\begin{aligned}
\mathrm{T}_{50}= & \text { cons }+\alpha_{1} \mathrm{sc}+\alpha_{3} \mathrm{wb}+\alpha_{4} \mathrm{sp}+\alpha_{12} \mathrm{scfc}+\alpha_{13} \mathrm{scwb} \\
& +\alpha_{34} \mathrm{wbsp}+\alpha_{33} \mathrm{wb}^{2}+\alpha_{44} \mathrm{sp}^{2}
\end{aligned}
$$

\section{Compressive Strength Models of HFC:}

The compressive strength is affected by many variables, including the $\mathrm{w} / \mathrm{b}$, the $\mathrm{sp}$, the aggregate combination, and the binder combination, which the binder combination is much complicated. In the research, the 7-day, 28-day, and 90-day compressive strength models were derived by statistical analysis and the proposed models as follows:

$\mathrm{fc}^{\prime} 7=\mathrm{cons}+\alpha_{1} \mathrm{sc}+\mathrm{scwb}+\mathrm{scsp}+\alpha_{23} \mathrm{fcwb}+\alpha_{24} \mathrm{fcsp}+\alpha_{11} \mathrm{sc}^{2}$

$\mathrm{fc}^{\prime} 28=\mathrm{cons}+\alpha_{3} w b+\alpha_{4} \mathrm{sp}+\alpha_{13} \mathrm{scwb}+\alpha_{11} \mathrm{sc}^{2}+\alpha_{22} \mathrm{fc}^{2}$

$\mathrm{fc}^{\prime} 90=\mathrm{cons}+\alpha_{2} \mathrm{fc}+\alpha_{3} w b+\alpha_{14} \mathrm{scsp}+\alpha_{23} \mathrm{fcwb}+\alpha_{24} \mathrm{fcsp}$

$$
+\alpha_{11} \mathrm{sc}^{2}
$$

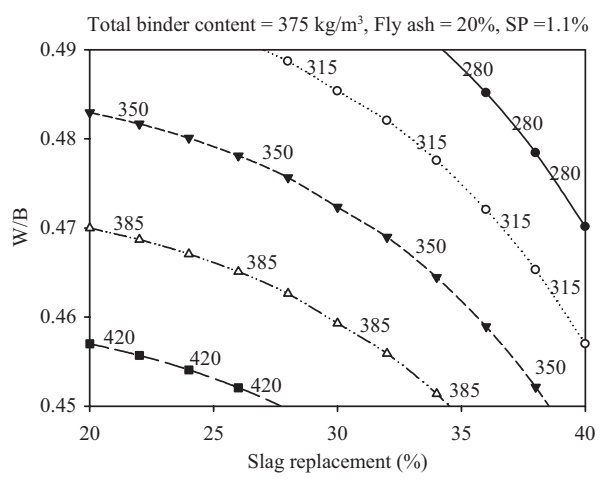

(a) Relation between GGBS and w/b

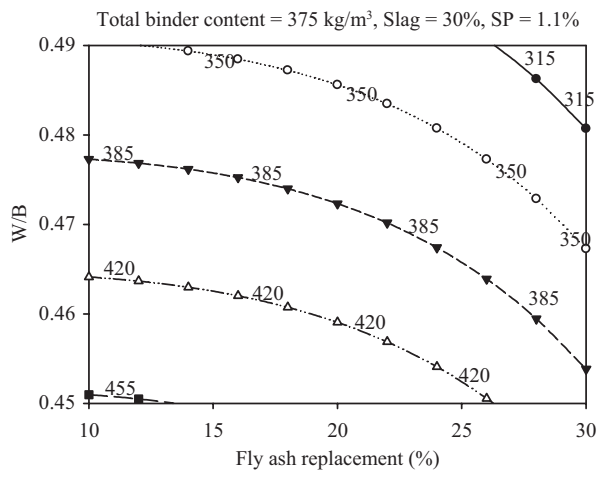

(b) Relation between Fly ash and w/b

Fig. 9. Typical response chart for prediction of 28-day compressive strengths.

The response charts for 28-day compressive strength are developed and illustrated in Fig. 9. The Fig. 9(a) represented that the relation between GGBS replacement and w/b at given $20 \%$ Fly ash replacement and $1.1 \%$ sp. It is feasible to maintain the same compressive strengths by combination with GGBS replacement and w/b. As can be seen from Fig. 9(a), the compressive strength is maintained $350 \mathrm{kgf} / \mathrm{cm}^{2}$ with reducing the w/b 0.04 to increase $20 \%$ GGBS replacement. The similar tendency is observed in Fig. 9(b), the compressive strengths can be maintained with combination with Fly ash and $\mathrm{w} / \mathrm{b}$.

Fig. 10 shows the isocurves of the variation of the compressive strength at 7,28, and 90 days with the different replacement of GGBS and Fly ash, which contains w/b $=0.47$ and $\mathrm{sp}=1.1 \%$. Fig. 10(a) shows that the increase of GGBS and Fly ash replacement led to a decrease in the compressive strength at 7 day. It can be found that some combination of GGBS and Fly ash replacement increase 28-day compressive strength. For example, the highest compressive strength is found in the below right rather than in the below left of the Fig. 10(b). The same result is found in the Fig. 10(c), the highest compressive strength is in the below right. From the above results, the highest compressive strength moves to the below right from the below left follow the time in the Figs. 10(a), 10(b), and 10(c). The phenomenon is resulted from pozzolanic effect of GGBS and Fly ash, and the 


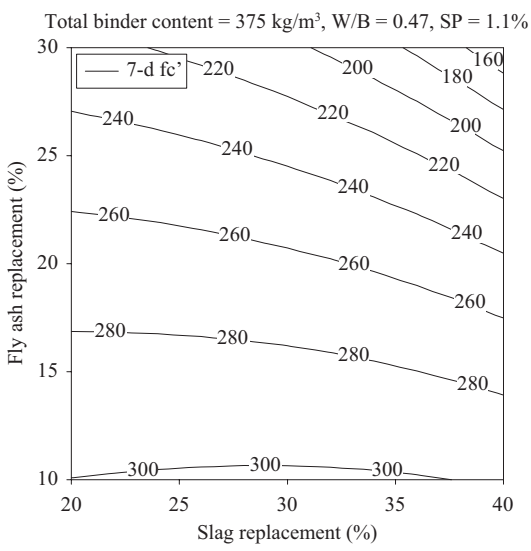

(a) Isocurve of 7-day fc'

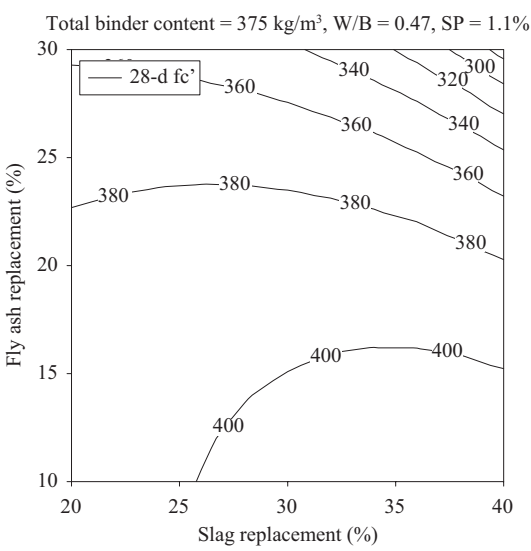

(b) Isocurve of 28-day fc'

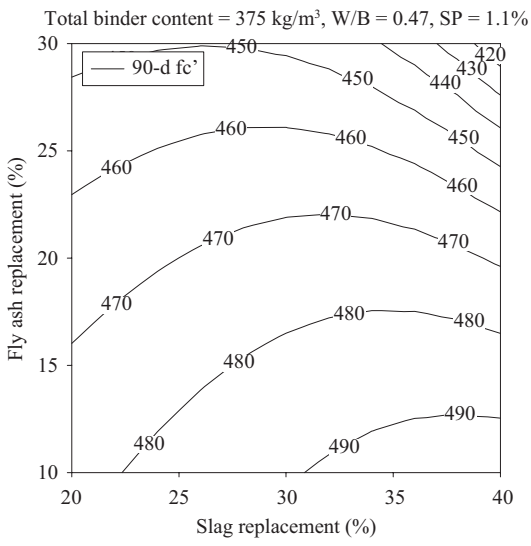

(c) Isocurve of 90-day fc'

Fig. 10. Influence of GGBS and Fly ash replacement on 7-day, 28-day, and 90-day compressive strength.

pozzolanic effect of GGBS is better than Fly ash. As can be seen from Fig. 10, the HFC mixture design can be optimized with the combination of GGBS and Fly ash replacement.

\section{The RCP Model of HFC:}

The basic factors influencing the reinforcing steel corrosion are the oxygen, the water, and the chloride. The chloride plays a major role in the corrosion of reinforcing bars. The

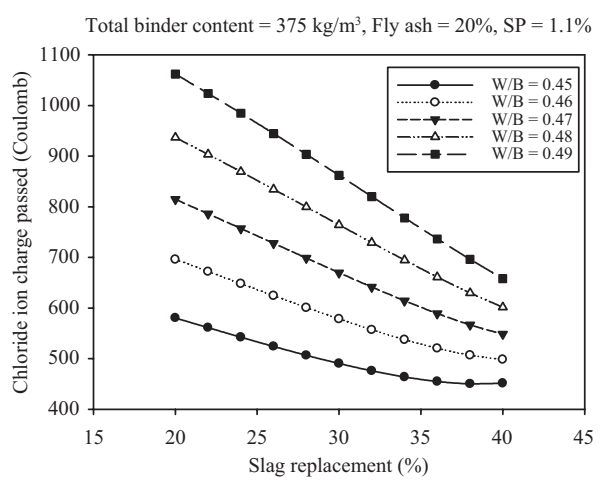

(a) Influence of GGBS and w/b on RCP

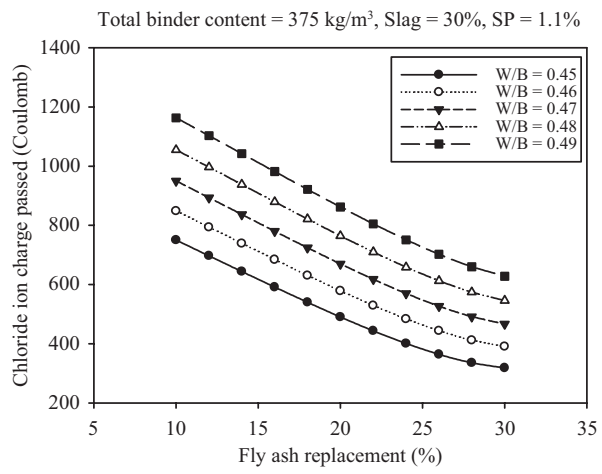

(b) Influence of Fly ash and w/b on RCP

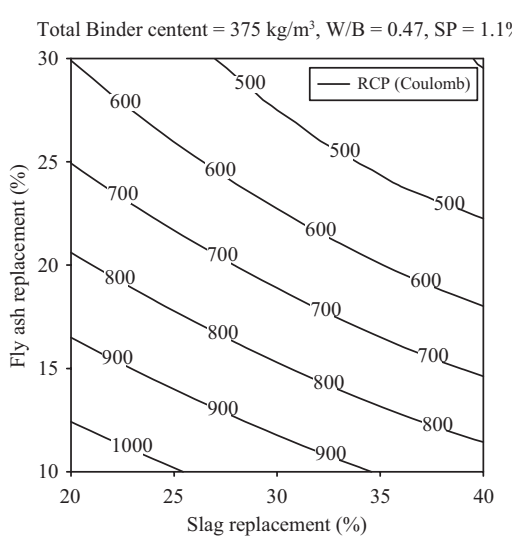

(c) Influence of GGBS and Fly ash on RCP

Fig. 11. Influence of multi-parameters on RCP.

corrosion behavior of steel bars induced by internal chlorides in concrete and can result in the deterioration of concrete [18]. In the research, the RCP model was developed to evaluate the ability of resistance to chloride ion penetration of the HFC with the w/b, GGBS replacement, and Fly ash replacement. The RCP model is given in Eq. (7). The Fig. 11 shows that the influence of four parameters on the resistance to chloride ion penetration. The charts can be observed that the ability of resistance to chloride ion penetration increases significantly by reducing the $w / b$. At the same time, it can be found the similar effect on the pozzolanic material. At given $w / b=0.47$ and the $20 \%$ Fly ash as cement replacement, the charge passed 
can be reduced from 800 to 550 coulombs with an increase from 20 to $40 \%$ in GGBS replacement. Furthermore, the charge passed can be reduced from 950 to 460 with a $20 \%$ increment or the Fly ash, while the w/b $=0.47$ and the $30 \%$ GGBS as cement replacement were given. The influence of GGBS and Fly ah replacement on the RCP, with fixed w/b = 0.47 and $\mathrm{sp}=1.1 \%$, are observed in Fig. 11(c). As the diagram indicates, the total charge passed is below 500 coulombs while the GGBS and Fly ash replacements are more than the $60 \%$ of total binder content.

$$
\begin{aligned}
\mathbf{R C P}= & \text { cons }+\alpha_{1} \mathrm{sc}+\alpha_{2} \mathrm{fc}+\alpha_{4} \mathrm{sp}+\alpha_{13} \mathrm{scwb}+\alpha_{11} \mathrm{sc}^{2}+\alpha_{22} \mathrm{fc}^{2} \\
& +\alpha_{33} \mathrm{wb}^{2}+\alpha_{44} \mathrm{sp}^{2}
\end{aligned}
$$

\section{The Carbonation Model of HFC:}

The primary factors influencing carbonation rate are the diffusivity/permeability, the reserve alkalinity, the environmental carbon dioxide concentration, and the exposure condition [12]. The greater carbonation resistance derived from the lower permeability can reduce the inward diffusion of carbon dioxide into the concrete. The permeability of concrete is affected by $w / b$, the pore structure of concrete, and the timely curing. The lower permeability and greater carbonation resistance concrete can be obtained from reducing $w / b$, and improving pore structure with pozzolanic materials. On the other hand, the reserve alkalinity is considered to resist the carbonation. The reserve alkalinity is from calcium hydroxide that arises from cement, and the more cement content the more calcium hydroxide to against carbon dioxide. On the contrary, the more replacement as cement of GGBS and Fly ash result in lower reserve alkalinity. The w/b, the pozzolanic material, and the dosage of sp were considered in the study, for a given the carbon dioxide concentration and the exposure condition. The carbonation of HFC is as follows:

$$
\begin{aligned}
\text { Carbonation }= & \text { cons }+\alpha_{1} s c+\alpha_{2} f c+\alpha_{12} s c f c+\alpha_{13} s c w b \\
& +\alpha_{23} f c w b+\alpha_{33} w b^{2}
\end{aligned}
$$

The response charts for the carbonation depth are developed and illustrated in Fig. 12. As the increment of GGBS replacement, there is a slight increase of carbonation depth with low w/b, there is, however, a steep rise of carbonation depth with high w/b, which can be observed in Fig. 12(a). At the same time, the similar phenomenon is represented in the Fig. 12(b). This is a manifestation of the increment of the w/b and pozzolanic materials content affect the carbonation rate significantly. This is no disagreement on this point that the increment of w/b result in raising pores and capillary porosity in the concrete, which is expected to increase the permeability. On the other hand, the GGBS and Fly ash as cement replacement are used to impact the capillary porosity of the paste and reducing the permeability of concrete. However, it needs to be considered that the more replacement of GGBS

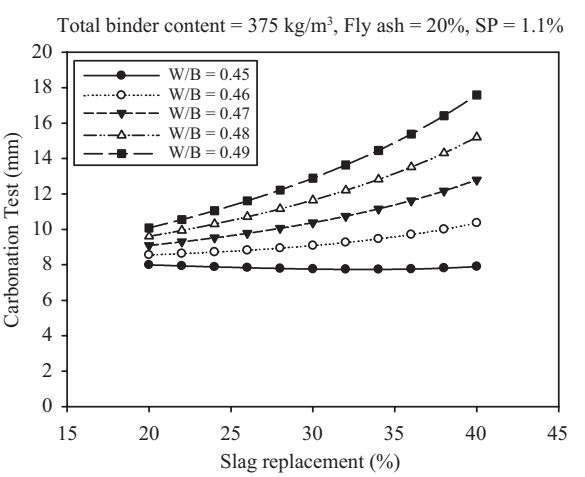

(a) Influence of GGBS and $w / b$ on carbonation

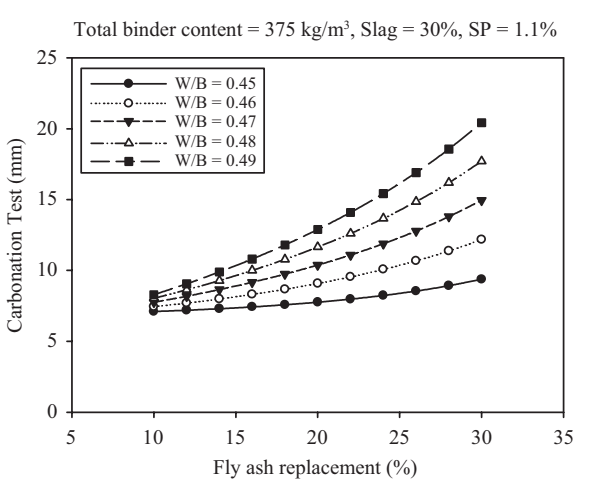

(b) Influence of Fly ash and w/b on carbonation

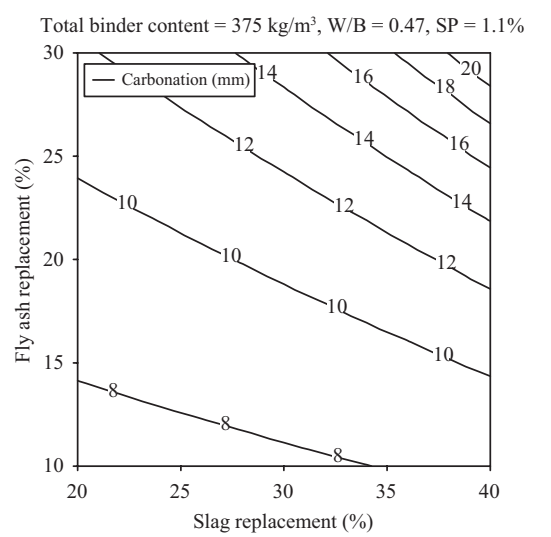

(c) Influence of GGBS and Fly ash on carbonation

Fig. 12. Influence of multi-parameters on carbonation.

and Fly ash the lower reserve alkalinity to resistance to the carbon dioxide. As mentioned above, for a given $\mathrm{w} / \mathrm{b}=0.47$ and $\mathrm{sp}=1.1 \%$, the largest carbonation is found in the above right in the Fig. 12(c).

\section{CONCLUSIONS}

In this research, 21 special concrete mixtures are used to probe into the influence of GGBS as cement replacement, Fly ash as cement replacement, w/b, sp on concrete fresh properties, compressive strength, and durability properties. The range of variables that we considers, the binder contain 375 
$\mathrm{kg} / \mathrm{m}^{3}, \mathrm{GGBS}$ as cement replacement from 10 to $50 \%$, Fly ash as cement replacement from 5 to $35 \%$, w/b between 0.44 and 0.50 , and sp between 0.9 and $1.1 \%$. Slump flow of mixtures to conform to the requirement of HFC (slump flow between 50 and $70 \mathrm{~cm}$ ), the 28-day compressive strength are between 289 415 kgf $/ \mathrm{cm}^{2}$. It seems reasonable to conclude that the medium strength HFC can be development successfully with low binder contain $\left(375 \mathrm{~kg} / \mathrm{m}^{3}\right)$ by suing proportional replacement cement with pozzolanic materials.

With the scope of this study, following conclusions can be drawn.

1. The four selected variables of GGBS replacement percentage, Fly ash replacement percentage, w/b, and sp percentage that present positive influence on the HFC, including fresh properties, strength, and durability by statistical analysis of the experiment data.

2. GGBS and Fly ash have capability to reduce the dosage of sp to achieve the same slump flow. The dosage of sp can be reduced with increment of GGBS and Fly ash as cement replacement for a constant slump flow. At given w/b and $\mathrm{sp}$ content, increasing GGBS and Fly ash replacement can increase the slump flow.

3. The $w / b$ and $s p$ have a greater influence on the viscosity, which $\mathrm{T}_{50}$ decreases with the increment of $\mathrm{w} / \mathrm{b}$ and $\mathrm{sp}$ content. On the other hand, For a given w/b and sp, the more GGBS replacement increases, the more $\mathrm{T}_{50}$ decreases and the more Fly ash replacement increases, the more $\mathrm{T}_{50}$ increases.

4. In the mechanical property, 7-day, 28-day, and 90-day compressive strength models were developed successfully to analyze the influence of four variables on compressive strength. In addition to this, the zones of pozzolanic effect were show in the isocurve of 90-day compressive strength.

5. In the durability of HFC, the charge passed was affected by w/b, GGBs replacement, and Fly ash. The increment of w/b led to increase the charge passed and increase concrete permeability. However, the charge passed can be reduced by increment of GGBS and Fly ash as cement replacement. It is important that the increment of Fly ash as cement replacement is benefic more than reducing the w/b to improve concrete permeability with containing the slump flow.

6. For the carbonation of HFC, the larger w/b led to high permeability, thereby resulting in lower carbonation resistance. On the other hand, The more pozzolanic material as cement replacement to decrease the reserve alkalinity, result in lower ability to resist the carbonation. It needs to be noted that the increase of GGBS and Fly ash replacement is more negative effects in terms of carbonation rate at high $\mathrm{w} / \mathrm{b}$.

7. This is a reasonable way to optimize mixtures of medium strength HFC by suing fresh properties, strength, and durability models to cut down the cost, improve workability with maintaining the compressive strength and the durability.

\section{REFERENCES}

1. Architectural Institute of Japan, Guidelines and Commentary of High Flowable Concrete-Materials, Mix Proportions, Manufacturing, and Placement, ed., AIJ, Tokyo (1997). (in Japanese)

2. ASTM C1611-09, "Standard test method for slump flow of selfconsolidating concrete," American Society of Testing Materials (2009).

3. ASTM C231-09, "Standard test method for air content of freshly mixed concrete by the pressure method," American Society of Testing Materials (2009).

4. ASTM C39-09, "Standard test method for compressive strength of cylindrical concrete specimens," American Society of Testing Materials (2009).

5. ASTM C1202-09, "Standard test method for electrical indication of concrete's ability to resist chloride ion penetration," American Society of Testing Materials (2009).

6. Bilodeau, A. and Malhotra, V. M., "High-volume Fly ash system: concrete solution for sustainable development," ACI Material Journal, Vol. 97, No. 1, pp. 41-48 (2004).

7. Chong, H. and de Larrard, F., "The rheology of fresh high-performance concrete," Cement and Concrete Research, Vol. 26, No. 2, pp. 283-294 (1996).

8. Ghezal, A. and Khayat, K., "Optimizing self-consolidating concrete with limestone filler by using statistical factorial design methods," ACI Material Journal, Vol. 99, No. 3, pp. 264-273 (2003).

9. Greene, W. H., Econometric Analysis, 5th Edition, Prentice-Hall, New York (2003).

10. Japanese Society of Civil Engineering, Guide to Construction of High Flowing Concrete, JSCE, Gihoudou Pub., Tokyo (1998). (in Japanese)

11. Khayat, K. H., Ghezal, A., and Hadriche, M. S., "Development of factorial design models for proportioning self-consolidating concrete," in: Malhotra, V. M. (Ed.), Nagataki Symposium on Vioion of Concrete: 21 st Century, June, pp. 173-197 (1998).

12. Mark, G., "Fundamentals of durable reinforced concrete," 11th Modern Concrete Technology, Spon Press, London (2002).

13. Papadakis, V. G., "Effect of supplementary cementing materials on concrete resistance against carbonation and chloride ingress," Cement and Concrete Research, Vol. 30, pp. 291-299 (2000).

14. Papadakis, V. G., Vayenas, C. G.., and Fardis, M. N., "Fundamental modeling and experimental investigation of concrete carbonation," ACI Materials Journal, Vol. 88, pp. 363-373 (1991).

15. Patel, R., Hossain, K. M. A., and Shehata, M., "Development of statistical models for mixture design of high-volume Fly Ash self-consolidating concrete," ACI Materials Journal, Vol. 101, pp. 294-302 (2004).

16. RILEM, Measurement for Hardened Concrete Carbonation Depth, TC14-CPC, CPC-18, 1988, included in RILEM compendium published by E \& FN Spon, Chapman \& Hall, (1994).

17. Roper, H. and Baweja D., "Carbonation-chloride interactions and their Influence on corrosion rates of steel in concrete," in: Malbotra, V. M. (Ed.), Durability of Concrete, ACI SP-126, pp. 295-316 (1991).

18. Safawi, M. I. and Iwaki, I., "The segregation tendency in the vibration of high fluidity concrete," Cement and Concrete Research, Vol. 34, pp. 219-226 (2004).

19. Sato, K., Hara, M., Araki, S., Ikeda, S., Hirai, K., and Sakamato, M., "Non-Segregation underwater concrete composed of ultra high-fine slag," NKK Technical Review, No. 61, pp. 75-82 (1999).

20. Schmidt, S. R. and Launsby, R. G., Understand ing Industrial Designed Experiments, 4th Edition, Kiemele, M. J. (Ed.), Air Academic Press, Colorado Springs, Colo., pp. 1-48 (1994).

21. Sonebi, M., "Applications of statistical models in proportioning medium-strength self-consolidating concrete," ACI Materials Journal, Vol. 101, pp. 339-346 (2004).

22. Sonebi, M., "Mdeium strength self-compacting concrete containing Fly ash: Modelling using factorial experimental plans," Cement and Concrete Research, Vol. 34, pp. 1199-1208 (2004).

23. Wooldridge, J. M., Introductory Econometrics - A Modern Approach, 4th Edition, South-Western Cengage Learning, Mason, Ohio ( 2009). 